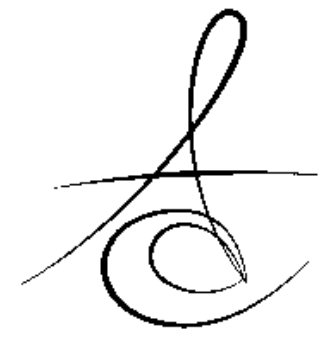

\title{
FARKLI RETROGRAD DOLGU MATERYALLERİNİN APİKAL DOKULAR ÜZERİNDEKİ İYİLEŞMEYE ETKİSİNİN RETROSPEKTİF OLARAK DEĞERLENDİRİLMESI
}

\section{THE EFFECT OF DIFFERENT RETROGRADE FILLING MATERIALS ON PERIAPICAL TISSUE HEALING: A RETROSPECTIVE STUDY}

\author{
Dr. Öğr. Üyesi Nazife Begüm KARAN*
}

Dr. Öğr. Üyesi Banu ARICIOĞLU*

Makale Kodu/Article code: 3518

Makale Gönderilme tarihi: 16.12 .2017

Kabul Tarihi: 16.10 .2018

\section{öz}

Amaç: Bu çalışmanın amacı farklı retrograd dolgu materyalleri kullanılarak kök ucu rezeksiyonu uygulan- mış dişlerde doku iyileşmesinin retrospektif olarak değerlendirilmesi ve başarılı olarak gözlemlenen tedavi şeklinin rapor edilmesidir.

Gereç ve Yöntem: Kök ucu rezeksiyonu endikasyonu bulunan tek köklü ve tek kanallı 330 diş, aynı hekim tarafından, 2014-2017 yılları arasında farklı retrograd dolgu materyalleri kullanılarak tedavi edilmiştir. Periapikal dokulardaki iyileşme radyografiler kullanılarak retrospektif olarak değerlendirilmiştir. Kullanılan retrograd dolgu materyaline göre 4 ana grup ve sadece rezeksiyon yapılan bir kontrol grubu oluşturuldu; Grup 1: (Trombositten Zengin Fibrin / Platelet Rich Fibrin): PRF, Grup 2: Amalgam, Grup 3: (Mineral Trioxide Aggregate) MTA ve Grup 4: PRF+MTA. Uygulanan yön- temlere göre gruplandırımış dişler, operasyon öncesi ve sonrası radyografik incelemeler eşliğinde, önceden eğitim verilmiş, çalışma dışında bulunan 2 tarafsız hekim tarafından Rud ve ark'larının tanımladığı 4 parametreli skorlama yöntemi kullanılarak değerlen- dirildi. Elde edilen veriler SPSS 21 paket programı ile Kruskal Wallis $\mathrm{H}$ ve Mann-Whitney $\mathrm{U}$ test kullanarak istatistiksel olarak analiz edildi.

Bulgular: Kontrol grubu ile çalışma grubu 1, 3 ve 4 arasında anlamlı bir fark bulunmadı. Kontrol grubu ile grup 2 arasında ise istatistiksel olarak anlamlı fark tespit edildi $(p<0.05)$. MTA uygulanan gruptaki başarı oranı $\%$ 57,97 olmasına rağmen gruplar arasındaki karşılaştırmada istatistiksel olarak anlamlı fark bulunmadı ( $p>0.05)$.

Sonuç: Bu çalışmanın sonucunda, kök ucu rezeksiyonu yapılmış dişlerde PRF, MTA veya PRF+MTA uygulamasının, retrograd dolgu uygulanmadan gerçek- leştirilen rezeksiyon vakaları ile benzer oranda iyileşme gösterdiği tespit edildi. Ancak; retrograd dolgu olarak amalgam kullanımının iyileşmeyi olumsuz etkilediği sonucuna varıldı.

Anahtar Sözcükler: Apikal rezeksiyon, MTA, PRF, Retrograd dolgu, Retrospektif çalışma

\section{ABSTRACT}

Aim: The aim of this study is to retrospectively assess the effects of different retrograde filling materials to periapical tissue healing, and to report the best treatment option considering the healing parameters.

Materials and Methods: Apical resection cases performed by the same physician between 2014-2017 were evaluated according to the healing status of the periapical tissue retrospectively. 330 teeth with a single canal and a single root are included to the study, while teeth with multiple canals are excluded. Groups are divided into a control and four experimental groups; Group 1: (Platelet Rich Fibrin) PRF, Group 2: Amalgam, Group 3: (Mineral Trioxide Aggregate )MTA, Group 4: PRF + MTA respectively. Periapical healing of the teeth were evaluated by pre-trained 2 independent clinicians which are out-of-the study, by means of scoring the radiological findings according to Rud et al. The obtained values were statistically analyzed by Kruskal Wallis $\mathrm{H}$ and MannWhitney U test using SPSS 21 software.

Results: No significant difference were found between control group and the experimental group 1, 3 and 4 . There were a statistically significant difference between the control group and the experimental group 2 ( $p$ $<0.05$ ). Although the success rate in the MTA group was $57.97 \%$, the comparison between the other groups are not statistically significant ( $p>0.05$ ).

Conclusion: PRF, MTA or PRF + MTA administration in apically resected teeth showed a similar improvement to resected cases without retrograde filling. The use of amalgam as a retrograde filler adversely affected recovery. The data obtained in this study are consistent with the literature in general.

Keywords: Apical, Resection, Mta, Prf, Retrograde, Retrospective

\footnotetext{
* (Sorum/u Yazar):Recep Tayyip Erdoğan Universitesi Diş Hekimliği Fakültesi Ağız, Diş ve Çene Cerrahisi AD,Rize.

${ }^{* *}$ Recep Tayyip Erdoğan Universitesi Diş Hekimliği Fakültesi Endodonti AD, Rize.
} 


\section{Gíriş}

Kök kanalı içerisinde bulunan mikroorganizmalar ve toksinleri periapikal bölgeye ulaşarak bazı enflamatuar değişiklikler oluştururlar. ${ }^{1}$ Kök kanallarının uygun yöntemler ile temizlenmesi, dezenfekte edilmesi ve sızdırmaz bir şekilde doldurulması periradiküler iyileşme için \%95 oranına varan başarı sağlar. ${ }^{2}$ Ancak; tekrarlanan başarısız tedavilerde; kök kanalından apikale ulaşılamayan durumlarda, periapikal kistik oluşumların varlığı ya da inatçı enfeksiyon vakalarında, kök ucu rezeksiyonu (apikal rezeksiyon) işlemi yapılması gerekebilir. ${ }^{3}$ Apikal rezeksiyon işleminde amaç; kök ucunda bulunan nekrotik alan ile birlikte apikal parçanın bir bölümünün uzaklaştırılarak diş kaybının engellenmesidir. ${ }^{4}$

Sızdırmaz bir şekilde kök kanalının gutta-perka (GP) ya da diğer materyaller ile tıkanması, apikal rezeksiyon işleminin başarısı açısından önem taşır. Çalışmalarda, iyi doldurulmuş kanallarda yapılan apikal rezeksiyonda, yerleştirilen kök ucu (retrograd) dolgu maddesine bağlı olmaksızın iyileşmenin gerçekleştiği rapor edilmiştir. ${ }^{5}$ Buna karşın, pek çok ex-vivo çalışmada, kök kanalında bulunan bakterilerin periapikal dokulara geçişinin retrograd dolgu ile önlenebileceği bildirilmiş ve bu yaklaşım daha sonra rutin tedavi protokolü olarak kabul görmüştür. ${ }^{6,7}$

İdeal retrograd dolgu materyallerinde aranılan özellikler; periapikal dokular tarafından iyi tolere edilebilmesi, bakteriostatik olması, boyutsal değişime uğramaması, sızdırmaz bir apikal tıkama yapabilmesi ve uygulama kolaylığının olmasıdır. ${ }^{8}$ Günümüze kadar bu amaç için gümüş amalgam, gümüş konlar, çinko oksit ojenol, ısıtılmış GP, polikarboksilat siman, cam ionomer siman, altın yaprak, teflon, kompozit, kalsiyum fosfat içerikli biomateryaller, Süper-EBA, IRM ve Mineral Trioxide Aggregate (MTA) gibi çok çeşitli dolgu materyalleri önerilmiştir.

Amalgamın, kullanım kolaylığı ve ulaşılabilir olması, radyo-opak ve bakteriostatik özellik göstermesi, dokular tarafından iyi tolere edilebilmesi retrograd olarak ilk tercih edilen materyal olmasını sağlamış ve bugüne kadar pek çok hekim tarafından uygulanmıştır. Buna karşın kavite duvarları arasında boşluk meydana gelmesi, periapikal dokulara civa salınımı ve yumuşak dokularda korozyon yaratması beklenen başarıyı düşürmüştür. ${ }^{9}$ 1993'ten bu yana başarılı bir şekilde kök kanallarında kullanılan bir biyomateryal olan MTA, trikalsiyum silikat, trikalsiyum alüminat, trikalsiyum oksit ve silikat oksitten oluşan, hidrofilik bir materyaldir. Uygulandıktan 4 saat sonra amalgam sertliğine ulaşır. ${ }^{10}$ Biyolojik ve fiziksel üstünlüğü ile kök kanal sisteminde daha fazla tercih edilen bir materyal haline gelmiştir. Yapılan in-vivo ve in-vitro çalışmalarda materyalin iyi sızdırmazlık özelliğinin yanı sıra periapikal dokulara olan uyumu, hücresel yenilenmeyi tetikleyip sement yapımını ve kemik oluşumunu desteklediği gösterilmiştir. ${ }^{11,12}$

Platelet, lökosit, sitokin, kök hücre ve fibrinden zengin içeriği olan Trombositten Zengin Fibrin / Platelet Rich Fibrin (PRF)'nin doku iyileştirici özelliği olan bir biyomateryal olduğu bilinmektedir. Aynı zamanda PRF içerisinde bulunan bazı büyüme hormonlarının bir haftaya kadar dokuya salındığı ve bu şekilde osteojenik potansiyelin arttığı yapılan çalışmalarla desteklenmiştir. ${ }^{13-15}$ PRF, hastanın kendi dokusundan elde edilen, immunoloik reaksiyon yaratmadan dokuyu iyileştiren bir rezervuar olarak da tanımlanabilir. Apikal rezeksiyon sonrasında, apiko-marjinal defektlerde, iyileştirici özellikleri nedeniyle PRF tercih edilen bir materyal olmuştur. $^{16}$

Bu çalışmanın amacı, kök ucu rezeksiyonu sonrasında uygulanmış farklı materyallerin, periapikal iyileşmeye olan etkilerinin retrospektif olarak incelenmesidir. Başlangıç hipotezi, incelenen yöntemler arasında iyileşmede anlamlı farklılık bulunmadığı şeklinde kurulmuştur.

\section{MATERYAL VE METOD}

Bu çalışma Recep Tayyip Erdoğan Üniversitesi Klinik Araştırmalar Etik Kurulu tarafından retrospektif çalışma olarak onaylanmıştır. (Dosya No: 2017/44)

2014-2017 yılları arasında apikal rezeksiyon tanısı almış ve tek bir hekim tarafından gerçekleştirilmiş 330 olguda kullanılan farklı retrograd dolgu materyallerinin periapikal dokuya olan iyileşme etkisi, retrospektif olarak değerlendirildi. Olgulara ait apikal rezeksiyon öncesi ve sonrası kontrol radyografilerine hasta arşivlerinden ulaşıldı. Kullanılmış retrograd dolgu materyalleri ve yapılan işlemler bilgisayar sistemi üzerinden öğrenildi ve operasyon sonrası iyileşme durumları kaydedildi. Başlangıçta, kök ucu rezeksiyonu uygulanmış 450 olgu incelendi. Radyografik olarak 
tatmin edici ve yeterli seviyede kanal tedavisi uygulanmış, marjinal kemik kaybı bulunmayan, 2017 ekim ayına kadar en az 1 yıllık takibi olan, tek köklü ve tek kanallı dişler çalışmaya dahil edildi. Birden fazla kök kanalı bulunan dişler, iyileşmede oluşabilecek varyasyonların karışıkığa sebep olabilme intimaline karşılık çalışma dışı bırakııdı.

Çalışmaya dahil edilen 330 olgudan $75^{\prime} i$, rezeksiyon dışında herhangi bir işlem görmediğinden "Kontrol Grubu" olarak değerlendirildi. PRF uygulanan 69 vaka "Grup 1", Amalgam ile retrograd dolgu yapılan 49 vaka "Grup 2", MTA ile retrograd dolgu yapılan 69 vaka "Grup 3" ve hem MTA hem PRF'nin eş zamanlı uygulandığı 51 vaka ise "Grup 4" olarak belirlendi. (Tablo 1)

Operasyon öncesi ve 12 ay sonrası radyografiler, eğitim verilmiş ve çalışma hakkında bilgisi olmayan 2 hekim tarafindan, 4 parametreli skorlama sistemine göre değerlendirildi. ${ }^{17}$ Skorlama sisteminde; (1) tam iyileşme; (2) eksik iyileşme (yara dokusu); (3) belirsiz iyileşme; (4) yetersiz iyileşme şeklinde belirlendi. (Tablo 2) Sonuçlar istatistiksel olarak analiz edildi ve bulgular karşılaşııııldı.

Tablo 1. Uygulanan materyallerin Çalışma ve Kontrol Gruplarına göre dağılımı

\begin{tabular}{|l|l|l|}
\hline Gruplar & $\begin{array}{l}\text { Uygulanan } \\
\text { Materyal }\end{array}$ & $\begin{array}{l}\text { Uygulanan Diş } \\
\text { Sayısı }\end{array}$ \\
\hline Kontrol Grubu & - & 75 \\
\hline Grup 1 & PRF & 69 \\
\hline Grup 2 & Amalgam & 49 \\
\hline Grup 3 & MTA & 69 \\
\hline Grup 4 & MTA+PRF & 68 \\
\hline Toplam & & 330 \\
\hline
\end{tabular}

Tablo 2. Rud ve ark, tarafindan yapılan skorlama sistemi ${ }^{(17)}$

\begin{tabular}{lc}
\hline İyileşme Şekli & Skor \\
\hline Tam iyileşme & 1 \\
Eksik iyileşme & 2 \\
Belirsiz iyileşme & 3 \\
Yetersiz iyileşme & 4 \\
\hline
\end{tabular}

\section{İstatistiksel Analiz}

Verilerin istatistiksel analizinde SPSS 21 paket programı kullanıldı. Sıralı ölçümde verilen skorlar arasındaki anlamlı farklılık parametrik olmayan analiz yöntemlerden Kruskal Wallis $\mathrm{H}$ testi ile analiz edildi. İkili grup karşılaştırmaları ise, Mann-Whitney $U$ testiyle gerçekleştirildi. Tüm testlerde istatistiksel önem düzeyi $p=0.05$ olarak alınd.
Kontrol grubu ortalaması 1.80 , standart sapması 1,18 ve örneklem büyüklüğü 75 olarak bulundu. Çalışma gruplarının ortalaması 2,25, standart sapması 0,89 ve ortalama örneklem büyüklüğü 64 olarak hesaplandı. Anlamlılık düzeyinin $\mathrm{p}=0.05$ olması durumunda, testin gücü (power) 0,81 bulundu. Genel olarak, gücün 0.80 ve üzerinde olması istenildiğinden çalışmanın gücü istenilen düzeyde elde edildi. ${ }^{18}$ Skorlama yapan gözlemcilerin arasındaki tutarlılık istatistiksel olarak analiz edildi ve uyum $(0.701 \leq \mathrm{Kw} \leq 0,801)$ yüksek seviyede bulundu.

\section{BULGULAR}

Mevcut çalışmanın 12 aylık takip sonucunda gruplara ait başarı oranları Tablo 3'de belirtilmiştir. \% 57,97 oranı ile tam iyileşme en çok MTA grubunda izlenmiş bunu $\% 57,3$ ile kontrol grubu takip etmiştir. Yetersiz iyileşme \% 49,48 oranı ile en çok amalgam grubunda rastlanılmışır.

Kruskal Wallis $\mathrm{H}$ testi ile yapılan gruplar arası çoklu karşılaşıımada elde edilen ortalama \pm standart sapma değerleri Tablo 4'de sunulmuştur. Gruplar arası farkın istatistiksel olarak anlamlıı̆ı analiz edildiğinde, gruplar arası farkın anlamlı olduğu bulunmuştur. Burada sıralı ortalaması en yüksek olan Grup 2'dir.

Tablo 5'de Mann-Whitney $U$ testi ile ikili karşlaştırma sonuçlarına göre elde edilen $P$ değerleri gösterilmiştir. MTA, MTA+PRF uygulanan gruplar ile kontrol grubu arasında anlamlı fark gözlemlenmezken, amalgamın retrograd dolgu alarak kullanıldığı grup ile kontrol grubu arasında istatistiksel olarak anlamlı fark tespit edilmiştir $(p<0.05)$.

Tablo 3. Gruplara göre başarı oranları (\%)

\begin{tabular}{|l|l|l|l|l|l|}
\hline Gruplar & \multicolumn{4}{|c|}{ Skor } \\
\hline & $\begin{array}{l}\text { Skor } \\
\mathbf{1}\end{array}$ & $\begin{array}{l}\text { Skor } \\
\mathbf{2}\end{array}$ & $\begin{array}{l}\text { Skor } \\
\mathbf{3}\end{array}$ & $\begin{array}{l}\text { Skor } \\
\mathbf{4}\end{array}$ \\
\hline Kontrol & 53.7 & 17.3 & 4 & 21.33 & \\
\hline Grup 1(PRF) & 40.57 & 27.53 & 18.11 & 13.76 & \\
\hline $\begin{array}{l}\text { Grup } \\
\text { (Amalgam) }\end{array}$ & 6.18 & 13.4 & 30.92 & 49.48 & \\
\hline Grup 3 (MTA) & 57.97 & 9.42 & 23.18 & 9.42 & \\
\hline $\begin{array}{l}\text { Grup } \\
\text { (MTA+PRF) }\end{array}$ & 43.17 & 37.25 & 19.06 & 0 & \\
\hline
\end{tabular}


Tablo 4. Kruskal Wallis $\mathrm{H}$ testi ile yapılan gruplar arası çoklu karşılaştırmada elde edilen ortalama \pm standart sapma değerleri.

\begin{tabular}{|l|l|l|}
\hline Gruplar & n & Sıra Ortalaması \\
\hline Kontrol Grubu & 75 & 145,20 \\
\hline Grup 1(PRF) & 69 & 167,21 \\
\hline Grup 2 (Amalgam) & 49 & $\mathbf{2 5 7 , 8 0}$ \\
\hline Grup 3 (MTA) & 69 & 139,02 \\
\hline Grup 4 (MTA+PRF) & 68 & 146,51 \\
\hline \multicolumn{2}{|c|}{$X^{2}=60.629 \quad$ sd:4 p $=0.000$} \\
\hline
\end{tabular}

Tablo 5. Mann-Whitney $U$ testi ile ikili karşılaştırma sonuçları.

\begin{tabular}{|c|c|c|c|c|c|c|}
\hline Gruplar & & & $\begin{array}{l}\text { Mean } \\
\text { Rank }_{1}\end{array}$ & $\begin{array}{l}\text { Mean } \\
\text { Rank }_{2}\end{array}$ & Z & p \\
\hline $\begin{array}{l}\text { Kontrol } \\
\text { Grup } 1\end{array}$ & Grubu & - & 67.14 & 78.33 & -1.668 & $\begin{array}{l}0.09 \\
5\end{array}$ \\
\hline $\begin{array}{l}\text { Kontrol } \\
\text { Grup } 2\end{array}$ & Grubu & - & 48.52 & 83.90 & -5.498 & $\begin{array}{l}0.0 \\
00\end{array}$ \\
\hline $\begin{array}{l}\text { Kontrol } \\
\text { Grup } 3\end{array}$ & Grubu & - & 74.50 & 70.33 & $-0,647$ & $\begin{array}{l}0.51 \\
8 \\
\end{array}$ \\
\hline $\begin{array}{l}\text { Kontrol } \\
\text { Grup } 4\end{array}$ & Grubu & - & 69.04 & 75.26 & -0.939 & $\begin{array}{l}0.34 \\
8\end{array}$ \\
\hline
\end{tabular}

$P<0.05$ : istatistiksel olarak anlam/ı

\section{TARTIŞMA}

Bu çalışmada, apikal rezeksiyon yapılmış olan dişlere uygulanan farklı cerrahi tedavi protokollerinin iyileşme üzerindeki etkileri, subjektif verilere dayandırılarak, objektif olarak değerlendirildi. Farklı kişiler tarafından incelenen bir çalışma, yalnızca bir gözlemci tarafından yapılan çalışmalara göre, daha yüksek geçerlilik ve güvenilirlik taşımaktadır. Değerlendirme sırasında incelenen görüntünün hangi tedavi yöntemi ile tedavi edildiğinin bilinmemesi gözlemcilerin bir tedaviyi diğerine tercih etmelerini engeller. ${ }^{19}$

Apikal rezeksiyon vakalarında uzun süreli başarıyı etkileyen en önemli faktörlerden birinin kanaIın doldurulma kalitesi olduğu bilinir. Yapılan bir çalışmada kanal dolgusunun sızdırmaz şekilde yapılmasının iyileşme üzerinde pozitif etkisi olduğu kanıtlanmıştır. ${ }^{20}$ Ancak; GP ile doldurulan kanalların rezeksiyon sonrasında kök ucunda uygun bir sızdırmazlık sağlayıp sağlamadığı netlik kazanmamıştır. Geleneksel olarak uygulanan apikal rezeksiyon işleminde kök ucu rezeksiyonu yapıldıktan sonra retrograd dolgu yerleştirilmesi gerekliliği de araştırmacılar arasında tartışma konusudur. ${ }^{21}$

Birçok çalışma, periapikal kemik doku iyileşmesinin kök ucu rezeksiyonundan sonra herhangi bir retrograd dolgu yerleştirilmesinden bağımsız olduğu sonucuna varmıştır. ${ }^{22,}{ }^{23}$ Bazı araştırmacılar ise GP ile yapılan kök kanalı dolgularının rezeksiyon işlemi sonrasında ek bir dolguya gerek kalmayacak düzeyde rezeksiyon alanında tıkanma sağladığını iddia etmektedirler. ${ }^{24} \mathrm{Bu}$ sonuçlar, bu çalışmada kontrol grubu olarak ele alınan GP ile doldurulmuş kanallarda yapılan rezeksiyon işlemi sonrası elde edilen sonuçlar ile korelasyon göstermektedir. Aynı zamanda, GP ortograd kök kanal dolguları içinde tercih edilen başlıca materyal olmasının yanı sıra retrograd olarak da kök ucunda hermetik bir tıkama sağlama amacıyla şekillendirilip kullanılmıştır. ${ }^{25,26}$

Retrograd dolgu maddesinin veya kök ucundaki mevcut kök kanal dolgusunun sızdırmazlık özelliğinin iyi olması apikal rezeksiyon prognozunu önemli şekilde etkiler. ${ }^{27}$ Dolgu malzemesi olarak kullanılan amalgamın önceleri yapılan çalışmalarda periapikal dokulara uyumluluğu ve gösterdiği yüksek marjinal adaptasyonu nedeniyle tercih edilebilir bir retrograd dolgu maddesi olabileceği iddia edilse $\mathrm{de}^{28,29}$, son zamanlarda yapılan çalışmalarda geç sertleştiği, sertleşirken büzülmeye uğradığı, çevre dokulara civa saldığı ve korozyona uğradığı bildirilmiş ve bu dezavantajlar araştırmacıları alternatif retrograd dolgu materyali arayışına yönlendirmiştir. ${ }^{30}$

Hızlı bir şekilde sertleşen ve kanla kontamine olmasına rağmen özelliğini yitirmeyen MTA'nın, periapikal lezyonlu dişler için başarılı bir tedavi olduğu ${ }^{11}$ ve amalgama göre daha iyi sızdırmazlık sağladığı gösterilmiştir. ${ }^{31}$ Kazem ve arkadaşlarının yaptığı çalışmada da amalgamın \%100 sızdırmaya neden olduğu kanıtlanmıştır. ${ }^{32}$ Literatürde mevcut çalışmaların sonuçları baz alınarak yapılan meta-analizde MTA'nın bakteri geçişini, Super EBA, amalgam veya IRM'den daha iyi önlediği rapor edilmiştir. ${ }^{33}$ Şimdiki çalışmanın sonuçlarına göre, retrograd dolgu materyali olarak amalgam uygulanan grupta iyileşme oranı en düşük bulunmuştur. Bu başarısızlık amalgamın yetersiz marjinal adaptasyonu ile birlikte neden olduğu bakteriyal sızıntı ve kontaminasyona bağlanabilir.

MTA ve ortagrad yolla doldurulmuş GP'nin, apikal rezeksiyon sonrası periapikal dokuda gözlenen iyileşme oranlarını karşılaştıran bir çalışmada, MTA uygulanan örneklerde başarı anlamlı oranda yüksek bulunmuştur. $^{21}$ Ancak, bu sonuç şimdiki çalışmanın bulgularıyla uyumlu değildir. Öyle ki, MTA'nın klinik kullanımını destekleyen pek çok olumlu özelliğe rağmen, uygulanmasının zor olması, sertleşme 
zamanının uzunluğu ve buna bağlı olarak özen gösterilmediği takdirde kolayca yıkanıp uzaklaşabileceği bildirilmiştir. ${ }^{34}$ Klinik uygulamada kök ucu dolgu materyali olarak kullanımına karar verilmişse hızlı sertleşen bir karışımın tercih edilmesi gerekmektedir. Yapılan deney çalışmalarında, partikül boyutlarının azaltılması ve nano parçacıkların eklenmesinin bu zamanı azalttığı gösterilmiştir. Bununla birlikte, kullanılan karışımın sıvı-toz oranı, çevresel faktörler (ortam $\mathrm{PH}, \mathrm{ISI}$ ), karışım içerisine hapsolmuş havanın MTA'nın sertleşme ve fiziksel özelliklerini etkileyebileceği gösterilmiştir. ${ }^{35}$ Şimdiki çalışmada retrograd dolgu materyali olarak MTA uygulanan grup ile sadece ortograd GP ile doldurulmuş grubun benzer başarı oranı göstermesi, MTA karışımının uygun olmayan çevresel ve klinik şartlarda hazırlanmış olmasından, uygulama yanlışlıklarından veya MTA'nın tam sertleşmemesine bağlı olarak kaviteden uzaklaşmış olmasından kaynaklanabilir.

Trombositten zengin fibrin (PRF), Plateletten zengin plazma (PRP)'ya daha iyi bir alternatif olarak önerilmiş, sitokinlerin, glikan zincirlerinin ve yapısal glikoproteinlerin sıkı bir şekilde bir araya geldiği otolog, yavaş yavaş polimerize olan, yüksek yoğunluklu, sikatrisyel fibrin ağıdır. ${ }^{36}$ Ancak; yapılan bir çalışmada çok sayıdaki biyomolekülün PRF'den eş zamanlı olarak salınmasının osteogenez için uygun bir ortam sağlayamadığı ve trombosit konsantrasyonlarının uyarıcı etkisinin osteoindüktif etkisinden ziyade, yumuşak doku iyileşmesinde etkili olduğu vurgulanmıştır. ${ }^{37,} 38$ Apiko-marjinal defektlerin incelendiği başka bir çalışmada, endodontik mikrocerrahi ile tedavi sonucunda yüksek bir başarı oranının elde edildiği ancak PRF eklenmesinin mutlak iyileşme sağlayamadığı rapor edilmiştir. ${ }^{39} \mathrm{Bu}$ çalışmaların bulgusu mevcut çalışma ile benzerlik göstermektedir. Şimdiki çalışmada da PRF eklenerek uygulanmış rezeksiyon olguları ile retrograd dolgu uygulanmayan kontrol grubu arasında iyileşme açısından anlamlı fark bulunamamıştır. Öyle ki, kemik lezyonunun şekil ve boyutunun yanı sıra, lezyonun etiyolojisi ve varoluş süresi, iyileşmeyi etkilemiş olup bu sonucun gözlemlenmesine neden olmuş olabilir. Bununla birlikte PRF membranı ince bir iskelet yapıdadır ve ağız dokuları gibi iyi vaskülarize bir ortamda hızla rezorbe olabilir. Ayrıca, PRF'deki fibrin içeriğinin zayıflığı, uygulama esnasında oluşan fiziksel kuvvetler karşısında, etkisinin azalmasına neden olup oral kavite gibi ortamlarda kullanımında zorluk yaratabilir. ${ }^{40,}{ }^{41}$ Dahası, PRF'nin hazırlığının çeşitli faktörlerle değişmesi (santifrüj vb.) membranın homojenitesini ve stabilitesini etkiler ve olası bir mikrobiyal veya kimyasal kontaminasyon da başarı şansını düşürür. Ayrıca, istatiksel anlam ifade etmemesine rağmen, yalnız MTA uygulanan grupta görülen iyileşme oranının PRF+MTA uygulanan gruba oranla yüksek bulunmasının, MTA'nın sertleşmesi sırasında PRF içerisinde çözülmesi nedeniyle kök ucunda istenilen tıkamayı sağlayamamış olmasından kaynaklanabilir.

Mevcut çalışmada amalgam grubunda diğer gruplar arasında anlamlı fark gözlemlendi ve tam iyileşme oranı \% 6.18 olarak hesaplandı. $(p<0.05)$. Tam iyileşme gözlenen olgu sayısı (Skor 1) oranları; MTA grubunda $(\% 57,97)$ en yüksek olarak belirlenmesine rağmen istatistiksel olarak diğer gruplarla anlamlı fark gözlemlenmedi. ( $p>0.05$ )

Kullanılan iki boyutlu radyolojik tetkik yönteminin periapikal dokunun gerçek iyileşme boyutunu yansıtamamasının yanı sıra, hastaların ara dönem kontrollerine riayet göstermemeleri nedeniyle ortak takip süresinin 12 ay olarak belirlenmiş olması da bu çalışmanın kısıtııı̆ındandır. Histolojik kanıt ile birlikte CBCT gibi üç boyutlu görüntüleme tekniği ile değerlendirme, dokulardaki iyileşmenin gerçek doğasını ve üç boyutlu ilişkisini belirlemek için daha iyi bir tanı aracı olabilir. Bu çalışma, daha ileri yöntemlerle ve daha büyük popülasyonlarda yapılacak olan çalışmalar için bir ön çalışma olarak nitelendirilebilir.

N.Begüm Karan:ORCID ID: 0000-0003-1027-792X Banu Arıcıoğlu: ORCID ID: 0000-0002-1124-1905

\section{KAYNAKLAR}

1. Sjögren U, Hägglund B, Sundqvist G, Wing K. Factors affecting the long-term results of endodontic treatment. J Endodont 1990; 16: 498504.

2. Siqueira JF, Rôças IN, Riche FN, Provenzano JC. Clinical outcome of the endodontic treatment of teeth with apical periodontitis using an antimicrobial protocol. Oral Surg Oral Med Oral Pathol Oral Radiol Endodont 2008; 106: 757-62.

3. Chandler $\mathrm{N}$, Koshy $\mathrm{S}$. The changing role of the apicectomy operation in dentistry. J Royal College Surg Edinburg 2002; 47: 660-7. 
4. Türker M. Yücetaş Ş. Ağız Diş Çene Hastalıkları ve Cerrahisi. Atlas Kitapçוlık Ticaret Ltd. Şti. Ankara, 1999: 205-45.

5. Metzger Z, Abramovitz I, Bergenholtz G. Apical periodontitis. Textbook of endodontology. Oxford, England: Blackwell 2003: 113-26.

6. Gartner A, Dorn S. Advances in endodontic surgery. Dent Clin North Am 1992; 36: 357-78.

7. Vignaroli PA, Anderson RW, Pashley DH. Longitudinal evaluation of the microleakage of dentin bonding agents used to seal resected root apices. J Endod 1995; 21: 509-12.

8. Chong B, Pitt Ford T, Hudson M. A prospective clinical study of Mineral Trioxide Aggregate and IRM when used as root-end filling materials in endodontic surgery. Int Endod J 2003; 36: 520-6.

9. Jesslén $P$, Zetterqvist $L$, Heimdahl $A$. Long-term results of amalgam versus glass ionomer cement as apical sealant after apicectomy. Oral Surg Oral Med Oral PatholOral Radiolog Endod 1995; 79: 101-3.

10. Islam I, Chng HK, Yap AUJ. Comparison of the physical and mechanical properties of MTA and Portland cement. J Endod 2006; 32: 193-7.

11. Torabinejad M. Mineral Trioxide Aggregate: Properties and Clinical Applications. Baskı. John Wiley \& Sons, 2014.

12. Torabinejad M, Rastegar AF, Kettering JD, Pitt Ford TR. Bacterial leakage of mineral trioxide aggregate as a root-end filling material. J Endod 1995; 21: 109-12.

13. Choukroun J, Diss A, Simonpieri A, Girard M-O, Schoeffler C, Dohan SL, Dohan AJ, Mouhyi J, Dohan DM. Platelet-rich fibrin (PRF): a secondgeneration platelet concentrate. Part IV: clinical effects on tissue healing. Oral Surg Oral Med Oral Pathol Oral Radiol Endodont 2006; 101: e56-e60.

14. Saluja H, Dehane V, Mahindra U. Platelet-Rich fibrin: A second generation platelet concentrate and a new friend of oral and maxillofacial surgeons. Ann Maxillofac Surg 2011; 1: 53.

15. Sharma A, Pradeep A. Autologous platelet-rich fibrin in the treatment of mandibular degree II furcation defects: A randomized clinical trial. Journal of periodontology, 2011, 82: 1396-403.
16. Angerame D, De Biasi M, Kastrioti I, Franco V, Castaldo A, Maglione M. Application of platelet-rich fibrin in endodontic surgery: a pilot study. Giornale Italiano di Endodonzia, 2015; 29: 51-7.

17. Rud J, Rud V, Munksgaard E. Long-term evaluation of retrograde root filling with dentin-bonded resin composite. J Endod 1996; 22: 90-3.

18. Pagano RR. Understanding statistics in the behavioral sciences. Baskı. Cengage Learning, 2012.

19. Chong B, Ford TP. The role of intracanal medication in root canal treatment. Int endod J 1992; 25: 97-106.

20. Rubinstein RA, Kim S. Long-term follow-up of cases considered healed one year after apical microsurgery. J J Endod 2002; 28: 378-83.

21. Christiansen R, Kirkevang LL, Hørsted-Bindslev P, Wenzel A. Randomized clinical trial of root-end resection followed by root-end filling with mineral trioxide aggregate or smoothing of the orthograde gutta-percha root filling-1-year follow-up. Int Endod J 2009; 42: 105-14.

22. Johnson BR. Considerations in the selection of a root-end filling material. Oral Surg Oral Med Oral PatholOral Radiol Endodont 1999; 87: 398-404.

23. Sauveur G, Sobel M, Boucher Y. Utilization of gutta-percha for retrograde root fillings. Dent Traumatology 2000; 16: 128-31.

24. Rapp EL, Brown CE, Newton CW. An analysis of success and failure of apicoectomies. J Endod 1991; 17: 508-12.

25. Amagasa T, Nagase $M$, Sato T, Shioda $S$. Apicoectomy with retrograde gutta-percha root filling. Oral Surg Oral Med Oral Pathol 1989; 68: 339-42.

26. Sauveur G, Sobel M, Boucher Y. Surgical treatment of a lateroradicular lesion on an invaginated lateral incisor (dens in dente). Oral Surg Oral Med Oral Pathol Oral Radiol Endodont 1997; 83: 703-6.

27. Chong B, Pitt Ford T, Hudson M. A prospective clinical study of Mineral Trioxide Aggregate and IRM when used as root-end filling materials in endodontic surgery §. Int Endod J2009, 42: 41420.

28. Mattison GD, von Fraunhofer JA, Delivanis PD, Anderson AN. Microleakage of retrograde amalgams. J Endod 1985; 11: 340-5. 
29. Tronstad L, Trope M, Doering A, Hasselgren G. Sealing ability of dental amalgams as retrograde fillings in endodontic therapy. J Endod 1983; 9: 551-3.

30. Niederman R, Theodosopoulou J. A systematic review of in vivo retrograde obturation materials. Int Endod J 2003; 36: 577-85.

31. Post LK, Lima FG, Xavier CB, Demarco FF, Gerhardt-Oliveira M. Sealing ability of MTA and amalgam in different root-end preparations and resection bevel angles: an in vitro evaluation using marginal dye leakage. Brazilian Dent J 2010; 21: 416-9.

32. Kazem M, Eghbal MJ, Asgary S. Comparison of bacterial and dye microleakage of different rootend filling materials. Iranian Endod J 2010; 5: 17.

33. Gupta SK, Saxena P, Pant VA, Pant AB. Adhesion and biologic behavior of human periodontal fibroblast cells to resin ionomer Geristore: a comparative analysis. Dent Traumatolog 2013; 29: 389-3.

34. Torabinejad M, Hong C, McDonald F, Ford TP. Physical and chemical properties of a new root-end filling material. J Endod 1995; 21: 349-53.

35. Lee SJ, Wu MK, Wesselink P. The effectiveness of syringe irrigation and ultrasonics to remove debris from simulated irregularities within prepared root canal walls. Int Endod J 2004; 37: 672-8.

36. Dohan DM, Choukroun J, Diss A, Dohan SL, Dohan AJ, Mouhyi J, Gogly B. Platelet-rich fibrin (prf). Oral Surg Oral Med Oral PatholOral Radiol Endod 2006; 101: e51-5.

37.Cömert Kılıç S. Maksiller sinüs augmentasyonlarında trombositten zengin plazmanin kullanımı: bir derleme çalışması. Atatürk Üniv Diş Hek Fak Derg 2016; 26: 350-7.

38. Soffer E, Ouhayoun JP, Anagnostou F. Fibrin sealants and platelet preparations in bone and periodontal healing. Oral Surg Oral Med Oral Pathol Oral Radiol Endod 2003; 95: 521-8.

39. Dhiman M, Kumar S, Duhan J, Sangwan P, Tewari S. Effect of platelet-rich fibrin on healing of apicomarginal defects: a randomized controlled trial. J Endod 2015; 41: 985-91.
40. Aroca S, Keglevich T, Barbieri B, Gera I, Etienne D. Clinical evaluation of a modified coronally advanced flap alone or in combination with a platelet-rich fibrin membrane for the treatment of adjacent multiple gingival recessions: a 6-month study. J Periodontol, 2009; 80: 244-52.

41. Cömert Kılıç S. İmplant cerrahisinde trikalsiyum fosfat içerikli greft materyaliyle yapilan sinüs augmentasyonu uygulamalarinda trombositten zengin plazma'nin etkinliğinin klinik, radyolojik ve histomorfometrik olarak değerlendirilmesi.Diss 2014.

\section{Yazışma Adresi}

Yrd.Doc.Dr. Nazife Begüm KARAN

Recep Tayyip Erdoğan Universitesi

Diş Hekimliği Fakültesi

Ağız, Diş ve Çene Cerrahisi Anabilim Dalı Rize, TÜRKİYE.

Tel: +90 (464) 2220002

E-mail: karanbegum@gmail.com 